\title{
Staged correction trajectory with hexapod external fixator for the satisfactory reduction of long bone shaft fracture
}

\author{
Yanshi Liu ${ }^{1 \dagger}$, Fei Wang ${ }^{2 \dagger}$, Kai Liu' ${ }^{1}$, Feiyu Cai ${ }^{1}$, Xingpeng Zhang ${ }^{3}$, Hong Li ${ }^{4}$, Tao Zhang ${ }^{5^{*}}$ and \\ Aihemaitijiang Yusufu ${ }^{1 *}$
}

\begin{abstract}
Backgroud: When the reduction of long bone shaft fracture fragments is performed by a hexapod external fixator, the collision and interference between bony ends often results in an incomplete reduction and a time-consuming procedure. The purpose of this study was to present and determine the clinical effectiveness of staged correction trajectory with hexapod external fixator in the reduction of a long bone shaft fracture.
\end{abstract}

Methods: A total of 57 patients with tibial shaft fractures treated by hexapod external fixator were retrospectively analyzed from June 2016 to February 2020. Thirty-one cases (Group I) underwent a conventional one-step reduction trajectory from June 2016 to July 2018. Starting in September 2018, the other twenty-six patients (Group II) underwent staged correction trajectory (three key points reduction trajectory of "distraction-derotation-reduction"). The demographic data, residual deformities before and after correction, number of repeated X-rays after the first postoperative X-ray, duration of deformity correction process, and external fixation time were analyzed. Johner-Wruhs criteria were used to evaluate the final clinical outcomes.

Results: All the 57 patients achieved satisfactory fracture reduction and bone union. There were no significant differences between the two groups in demographic data, residual deformities before and after correction, external fixation time, and final clinical outcomes $(p>0.05)$. The average number of repeated X-rays after the first postoperative $X$-ray and mean duration of deformity correction process in Group II (1.3 times, 2.9 days) were all less than those in Group I (2.3 times, 5.1 days) $(p<0.05)$.

Conclusion: Compared with the conventional one-step reduction trajectory, there is no differences in final clinical outcomes, but the staged correction trajectory provides less repeated X-rays and shorter reduction process duration.

Keywords: Fracture reduction, Hexapod external fixator, Staged correction trajectory, Tibial shaft fractures

*Correspondence: ztypp@163.com; ahmatjang@163.com

†Yanshi Liu and Fei Wang are contributed equally as the first and co-first authors to this study.

${ }^{1}$ Department of Trauma and Microreconstructive surgery, the First

Affiliated Hospital of Xinjiang Medical University, Urumqi, Xinjiang, China

${ }^{5}$ Department of Orthopedics and Trauma, Tianjin Hospital, Tianjin, China

Full list of author information is available at the end of the article

\section{Background}

Circular external fixators provide both stable threedimensional fixation and a degree of axial micromotion, promoting bone healing process and regeneration [1-3]. Minimal soft tissue damage and possibility of early weight bearing give to expect a good final outcome in bone fractures external fixation, especially in high energy fractures accompanied by poor surrounding soft tissues [4-7]. original author(s) and the source, provide a link to the Creative Commons licence, and indicate if changes were made. The images or other third party material in this article are included in the article's Creative Commons licence, unless indicated otherwise in a credit line to the material. If material is not included in the article's Creative Commons licence and your intended use is not permitted by statutory regulation or exceeds the permitted use, you will need to obtain permission directly from the copyright holder. To view a copy of this licence, visit http://creativecommons.org/licenses/by/4.0/. The Creative Commons Public Domain Dedication waiver (http://creativeco mmons.org/publicdomain/zero/1.0/) applies to the data made available in this article, unless otherwise stated in a credit line to the data. 
Hexapod external fixation (HEF) systems, such as the Taylor spatial frame (TSF) and TrueLok-Hex (TL-Hex), are derived from the traditional Ilizarov circular external fixator [8]. The HEF consists of two full or partial rings connected by six telescopic struts at special universal joints, providing the frame with six degrees of freedom. In this frame, the position of one ring can be changed in all space dimensions relating to the other one, by adjusting each strut length. This feature allowes the device to be used in bone deformities correction too. Over time, the hexapod external fixator has become more and more popular both in trauma-control and in definitive treatment of high-energy fractures [4, 9-12]. Stable contact between bone and HEF is necessary in fracture reduction or deformity correction planning based on x-rays. But, despite this stable contact, a try of one-step reduction trajectory can result in malposition due to the contact collision between bone fragments. Thenafter there is the need for additional reduction procedures and new X-rays checks, exposing the patient to further radiation.

At our department, staged correction procedures called three key point trajectory of "distraction-derotationreduction" were applied in fracture reduction process to resolve the contact collision between bone fragments. The purpose of this study was to present and to analyse the clinical significance of staged correction trajectory with hexapod external fixator in long bone shaft fracture reduction.

\section{Methods}

This retrospective study included 57 patients with acute tibial shaft fractures treated by hexapod external fixator (Tianjin Xinzhong Medical Instrument Co., Ltd., Tianjin, China) at the department of Trauma and Microreconstructive surgery, the First Affiliated Hospital of Xinjiang Medical University, from June 2016 to February 2020, including 39 males and 18 females with a mean age of 41 years (range 19-65years). The hexapod external fixation treatments were conducted due to trauma-control of high-energy complex fractures, fractures with poor surrounding soft tissues that were not suitable for internal fixation, and fractures that needed delayed soft tissue reconstruction. In any anatomical plane, postoperative deformities greater than $5^{\circ}$ or $10 \mathrm{~mm}$ need to be corrected [13].

Thirty-one cases (Group I) underwent a conventional one-step reduction trajectory from June 2016 to July 2018. Starting in September 2018, the other twenty-six patients (Group II) underwent staged correction trajectory (three key points reduction trajectory of "distraction-derotation-reduction"). All the treating procedures were performed by the same medical team. The demographic data, residual deformities before and after correction, number of repeated X-rays after the first postoperative X-ray, duration of deformity correction process, and external fixation time in all cases were documented and analyzed. This study was approved by the Ethical Committee of our institution.

\section{Fracture reduction procedures}

The residual deformities were evaluated by the immediately postoperative orthogonal anteroposterior (AP) and lateral X-ray, followed by the application of total residual program in the HEF system. Any deformities were corrected within 3 days by gradual strut adjustment according to the instrutions of computer analysis followed by oral analgesics were used in pain management. Repeated $\mathrm{X}$-rays and computer analysis were performed until satisfactory reduction was achieved.

In Group I (one-step reduction trajectory), all deformity parameters (angulation and translation in the anteroposterior, lateral, and axial view) were inputted into the HEF system program at once, and the deformity correction process was then performed according to the computer instructions.

As for Group II (staged correction trajectory), three key points reduction trajectory was performed (Figs. 1-2). A translation parameter in the axial view (within $10 \mathrm{~mm}$ according to our experience) was inputted into the HEF system program firstly to determine the lengthening of the given case, while the other five deformity parameters were set to zero. The first step of fracture reduction was performed according to the electronic prescription of the "distraction" key point (Fig. 2b and f). Subsequently, the five deformity parameters according to the postoperative X-rays (including angulation and translation in the $\mathrm{AP}$ and lateral view, angulation in the axial view) were inputted to determine rotation, while the translation parameter in the axial view was set to zero. The second step of fracture reduction was conducted depending on the electronic prescription of the "derotation" key point (Fig. 2c and g). Finally, a translation parameter in the axial view (original deformity combined with the "given" deformity in the first step) was inputted to determine the shortening, the other five deformity parameters were set to zero at the same time. The final fracture reduction was achieved using the electronic prescription of the "reduction" key point (Fig. 2d and h).

\section{Clinical effectiveness evaluation}

The reduction effectiveness was evaluated by the translation and angulation in the AP and lateral view, according to the standard orthogonal X-rays after the final reduction. The residual deformities were assessed by the same observer who was experienced in musculoskeletal radiology analysis using CorelDRAW X7 software. 


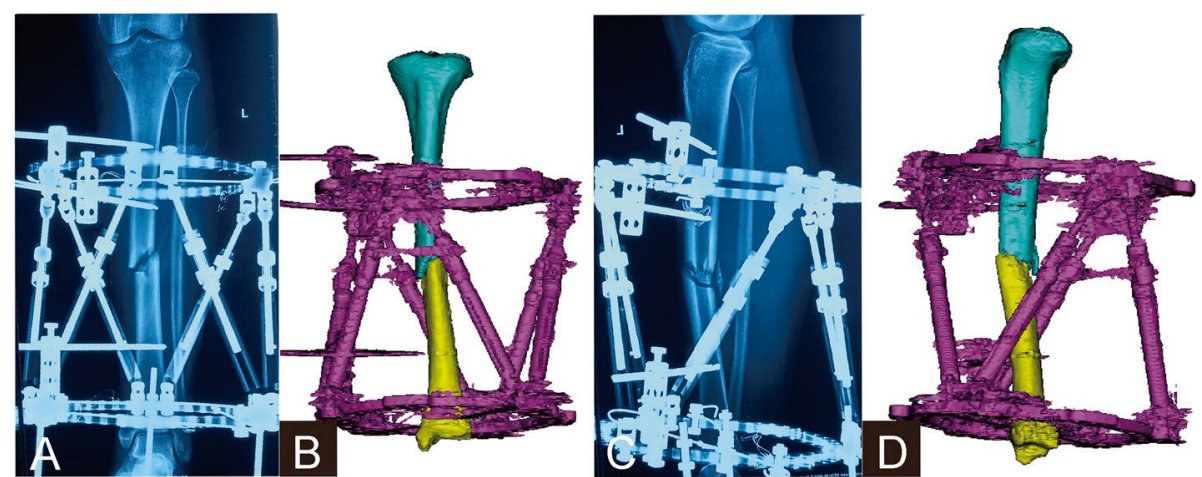

Fig. 1 A 41-year-old man with traumatic multidimensional displacement in tibia treated by the hexapod external fixator, and underwent staged correction trajectory. $\mathbf{a}$ and $\mathbf{b}$ Immediate postoperative X-rays and three-dimensional reconstruction in the AP view. c and $\mathbf{d} I m m e d i a t e$ postoperative $\mathrm{X}$-rays and three-dimensional reconstruction in the lateral view

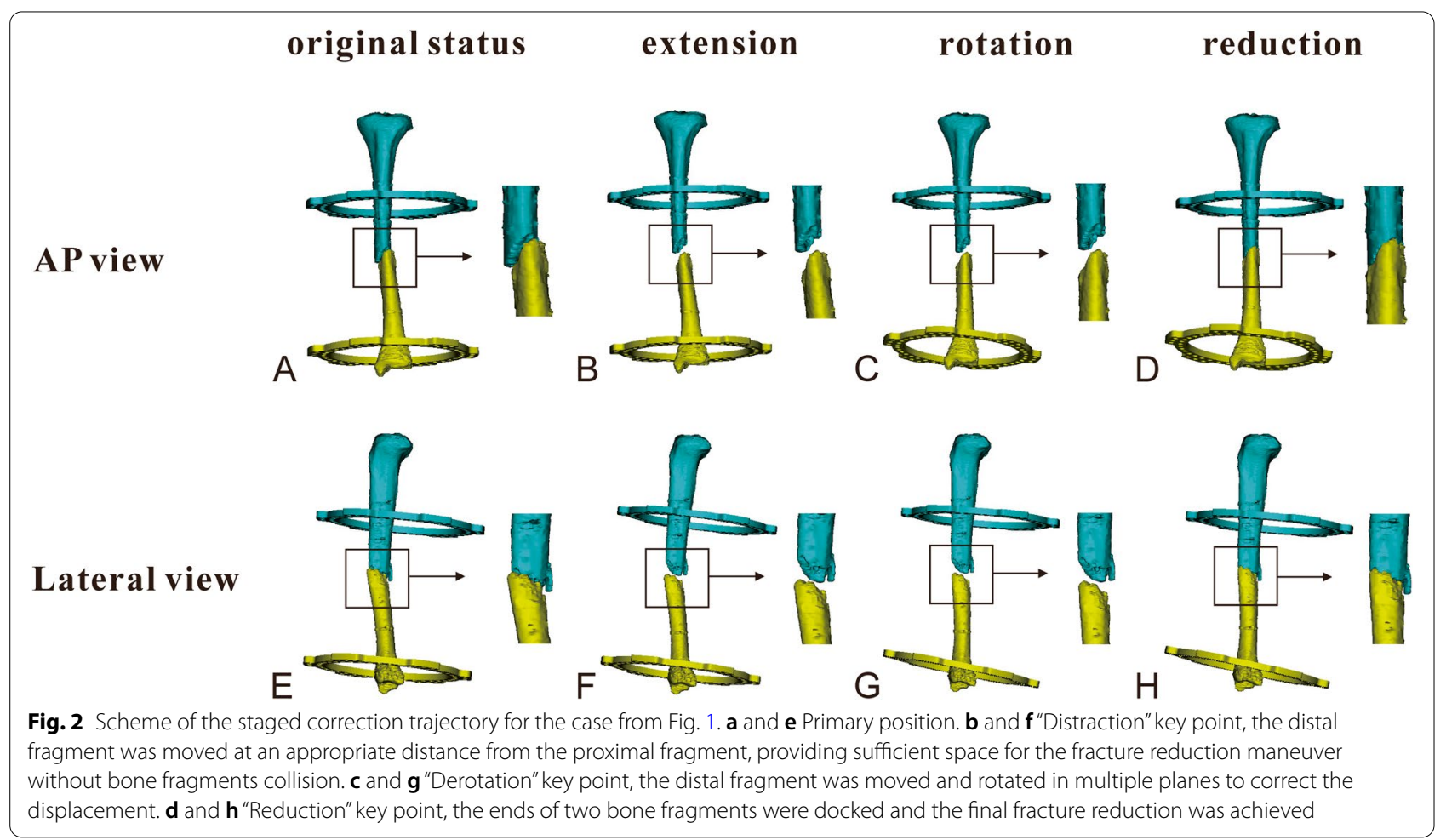

The patients were followed up monthly during the fracture healing time. The hexapod external fixation was terminated when X-rays confirmed sufficient union (corticalization in 3 of 4 cortices). All patients were followed up for a minimum of 12 months after the fixator removal. The final clinical outcomes were evaluated by the JohnerWruhs criteria [14] at the last clinical exam.

\section{Statistical analysis}

The SPSS 22.0 software was used for statistical analysis. Continuous variables were analyzed by
Independent-samples T-test. Count variables were analyzed by the Chi-square or Fisher's test. A statistically significant difference was set for $p<0.05$.

\section{Results}

All the 57 patients achieved satisfactory fracture reduction and bone union. The average follow-up after the hexapod external fixator removal was 17.9 months (1226 months), and no case was lost. Superficial pin tract infection was the most common complication during the external fixation treatment as expected, and they 
were successfully managed by daily pin site care and oral antibiotics. In addition, no patient developed sequestrum requiring debridement. Furthermore, no wires or pins loosening, reduction loss, neurovascular injury, and refracture were observed. Activities of daily life without significant difficulty were performed in all patients at the last exam.

There were no significant differences between the two groups in demographic data, residual deformities before and after correction, and external fixation time $(p>0.05)$. The average number of repeated X-rays after the first postoperative X-ray and mean duration of deformity correction process in Group II (1.3 times, 2.9 days) were less than those in Group I (2.3 times, 5.1 days) $(p<0.05)$. Typical cases are presented in Figs. 3 and 4.
Based on the Johner-Wruhs criteria, in Group I, there were excellent in 23 cases, good in 6 cases, and moderate results in 2 cases. Excellent in 19 patients, good in 5, and moderate results in 2 were observed in Group II. There were no statistically significant differences between the two groups $(p>0.05)$. More details are shown in Tables 1 and 2 .

\section{Discussion}

Combined with the Ilizarov circular external fixator and the Chasles theorem of six-axis motion $[15,16]$, the hexapod external fixator has played an important role in orthopedic and reconstructive surgery due to the unique type of multiplanar spatial deformities correction $[4,7-10,12,17,18]$. Initially developed for gradual

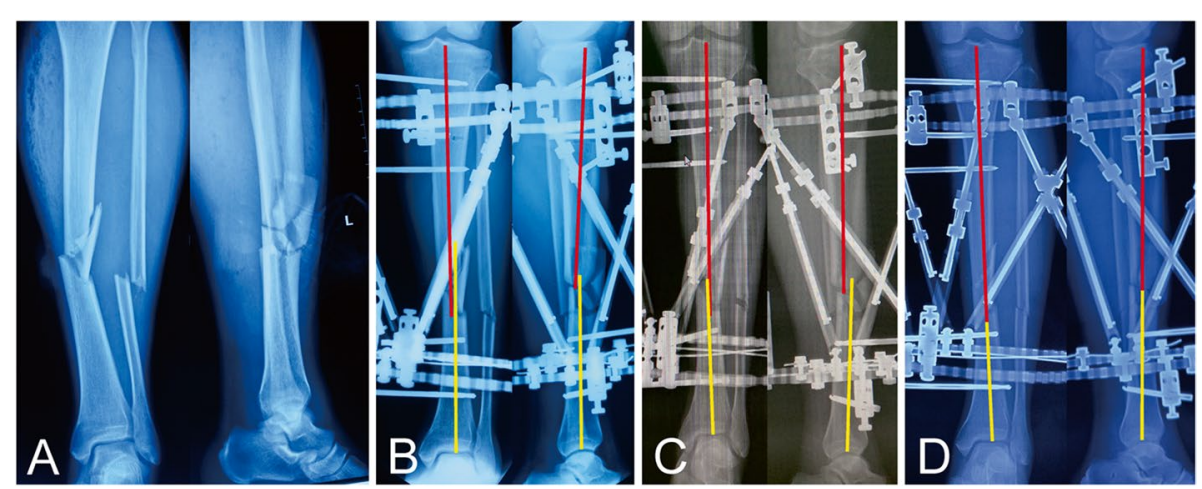

Fig. 3 A 49-year-old man with traumatic multidimensional displacement in tibia treated by the hexapod external fixator, performing conventional one-step reduction trajectory, this patient underwent two repeated $X$-rays after the first postoperative $X$-ray, and the deformity correction process took 6 days. a Traumatic $\mathbf{X}$-rays. $\mathbf{b}$ X-rays immediately after surgery. $\mathbf{c} X$-rays after the first correction. $\mathbf{d}$ X-rays after the second correction

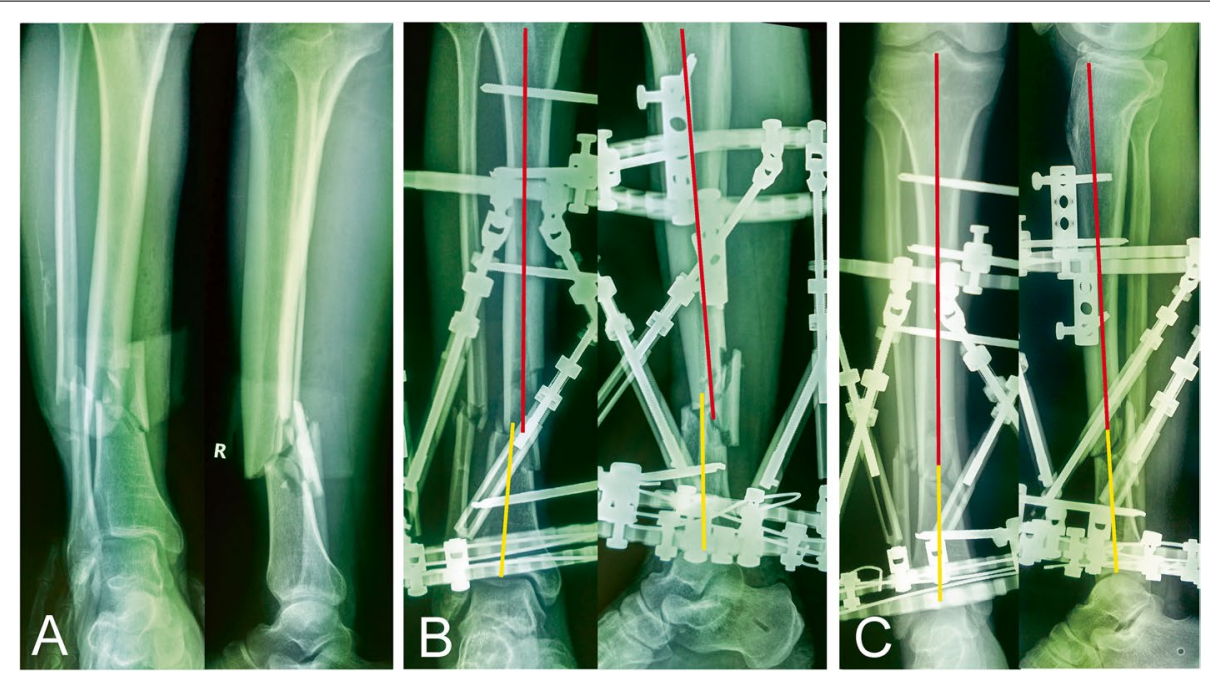

Fig. 4 A 52-year-old man with traumatic multidimensional deformity in tibia treated by the hexapod external fixator, performing staged correction trajectory, this patient had one repeated X-ray exposure after the first postoperative $X$-ray and a three-day of deformity correction process. a Traumatic X-rays. b X-rays after surgery. c X-rays after the first correction 
Table 1 Demographic data of the two groups

\begin{tabular}{|c|c|c|c|c|}
\hline & Group I & Group II & $t / x^{2}$ & $p$ value \\
\hline \multicolumn{5}{|l|}{ Patients } \\
\hline Male & 21 & 18 & 0.015 & 0.904 \\
\hline Female & 10 & 8 & & \\
\hline Age (year) & $40.6 \pm 11.9$ & $41.1 \pm 9.9$ & -0.170 & 0.865 \\
\hline \multicolumn{5}{|l|}{ Injury mechanism } \\
\hline Road traffic accident & 20 & 18 & 1.380 & 0.531 \\
\hline Fall from height & 4 & 5 & & \\
\hline Crushing injury & 7 & 3 & & \\
\hline \multicolumn{5}{|l|}{ Open/closed fracture } \\
\hline Open & 22 & 16 & 0.566 & 0.575 \\
\hline Closed & 9 & 10 & & \\
\hline \multicolumn{5}{|c|}{ Gustilo classification of the open fractures } \\
\hline Type I & 3 & 1 & - & 0.876 \\
\hline Type II & 4 & 3 & & \\
\hline Type IIIA & 13 & 9 & & \\
\hline Type IIIB & 2 & 3 & & \\
\hline Type IIIC & 0 & 0 & & \\
\hline \multicolumn{5}{|c|}{ OTA classification of fractures } \\
\hline A & 11 & 6 & 1.251 & 0.599 \\
\hline B & 16 & 17 & & \\
\hline$C$ & 4 & 3 & & \\
\hline $\begin{array}{l}\text { Time elapsed since the } \\
\text { injury to HEF installation } \\
\text { (day) }\end{array}$ & $3.3 \pm 1.4$ & $3.1 \pm 1.1$ & 0.332 & 0.741 \\
\hline
\end{tabular}

deformity correction process, the hexapod external fixator expanded its use in fracture and bone nonunion treatment $[11,12,18-20]$.

Using the hexapod external fixator, high theoretical accuracies of $1 / 1000000 \mathrm{in}$. and 1/10000 degrees are extreme for clinical practice, but it is acceptable in real to approximate correction accuracies of $1 \mathrm{~mm}$ and $1^{\circ}[15$, 21]. Accurate X-ray analysis of deformity and mounting parameters are crucial for the success of hexapod external fixation treatment. Although lots of satisfactory clinical outcomes have been manifested in the HEF treatment, no technique is perfect in fact, as most parameter measurement techniques are subjective and depend on human factors. Malcorrection or insufficient correction can result from some subtle errors in the parameter definition. Lots of previously published methods have been described to improve parameter accuracy, including CT scans, intraoperative fluoroscopy, postoperative $\mathrm{X}$-rays, and determination of the X-ray orthogonality [15, 22-30].

Abundant efforts have been described to obtain the standard orthogonal radiographs. Gantsoudes et al. [15] utilized equipment that is already available in a TSF treatment to obtain intraoperative orthogonal images, pointing out that their technique was quick, cheap, and easily reproducible. Ahrend et al. [28] had taken postoperative X-rays using a rotation rod, and the results suggested that the variability of rotation on X-rays was lower with the rotation rod, and more comparable X-rays could be obtained. Kanellopoulos et al. [24] described a noninvasive technique using a specially designed radiolucent frame to determine the reference ring precisely orthogonal in single exposures for each X-ray view. Deakin DE et al. [25] acquired perfectly aligned X-rays with the help of a frame-mounted spirit level. Wright et al. [27] described a silhouette technique to produce adequate orthogonal imaging. (shown in Table 3).

Some other studies have sought to improve the accuracy of measurements. Kucukkaya et al. [23] introduced a technique for determining the mounting parameters using computed tomography, and it was especially useful in cases with rotational deformity. Liu et al. [26] accurately measured the deformity and mounting parameters using the elliptic registration technique and three-dimensional reconstruction. Gessmann et al. [31] considered the mounting parameters can be accurately measured by $\mathrm{X}$-ray techniques using calibration markers and a software calibration tool.

The aforementioned techniques are based on precise parameter calculation or the orthogonality of radiographs, none of them focused on the influence of bony ends' collision on the effectiveness of fracture reduction process. This collision between irregular bony ends often results in an incomplete reduction or failed reduction. In those complex cases, this drawback always results in the need for repeating X-rays exposing the patient to further radiation and making the reduction procedure time-consuming.

In the present study, the three key points reduction trajectory of "distraction-derotation-reduction" was used to resolve this problem. In the whole process, the crucial step is "distraction" to provide sufficient space for the relative movement of the two bony ends. Accurate parameter measurements are very important during the process. In this study, including 57 patients with tibial shaft fractures treated by the HEF, there was not the difference between two groups in the final clinical outcome. Although both groups achieved good average outcomes, the average numbers of repeated X-rays after the first postoperative X-ray and mean durations of deformity correction process in Group II were all less than those in Group I. Furthermore, even though no significant difference was observed between the two goups, there was a trend that the mean external fixation time was shorter in Group II than that in Group I. Repeated reduction may be followed by local soft tissue damage of an acutely injured extremity, obstructing the wound and fracture 
Table 2 Clinical outcomes of the two groups

\begin{tabular}{|c|c|c|c|c|}
\hline & Group I & Group II & $t / x^{2}$ & $p$ value \\
\hline \multicolumn{5}{|l|}{ Residual deformities before correction } \\
\hline $\mathrm{T} 1(\mathrm{~mm})$ & $9.6 \pm 5.6$ & $8.5 \pm 5.2$ & 0.745 & 0.459 \\
\hline $\mathrm{A} 1\left(^{\circ}\right)$ & $5.5 \pm 2.5$ & $5.1 \pm 3.3$ & 0.596 & 0.553 \\
\hline $\mathrm{T} 2(\mathrm{~mm})$ & $8.3 \pm 3.3$ & $8.9 \pm 5.1$ & -0.505 & 0.616 \\
\hline $\left.\mathrm{A} 22^{\circ}\right)$ & $3.8 \pm 1.9$ & $4.4 \pm 2.1$ & -1.204 & 0.234 \\
\hline \multicolumn{5}{|l|}{ Residual deformities after correction } \\
\hline $\mathrm{T} 1(\mathrm{~mm})$ & $1.8 \pm 1.3$ & $1.2 \pm 1.1$ & 1.748 & 0.086 \\
\hline $\mathrm{A} 1\left(^{\circ}\right)$ & $0.7 \pm 0.8$ & $0.6 \pm 0.8$ & 0.720 & 0.475 \\
\hline $\mathrm{T} 2(\mathrm{~mm})$ & $1.2 \pm 1.1$ & $0.9 \pm 1.3$ & 0.859 & 0.394 \\
\hline $\left.\mathrm{A} 22^{\circ}\right)$ & $0.8 \pm 0.9$ & $0.7 \pm 0.9$ & 0.777 & 0.441 \\
\hline $\mathrm{N}$ (time) & $2.3 \pm 1.0$ & $1.3 \pm 0.5$ & 4.572 & $P<0.001$ \\
\hline Duration of deformity correction (day) & $5.1 \pm 1.9$ & $2.9 \pm 1.1$ & 4.914 & $P<0.001$ \\
\hline External fixation time (week) & $27.9 \pm 4.9$ & $27.2 \pm 1.9$ & 0.543 & 0.589 \\
\hline Follow-up (month) & $18.3 \pm 3.7$ & $17.5 \pm 4.7$ & 0.699 & 0.488 \\
\hline \multicolumn{5}{|l|}{ Johner-Wruhs criteria } \\
\hline Excellent & 23 & 19 & 0.212 & 1.000 \\
\hline Good & 6 & 5 & & \\
\hline Moderate & 2 & 2 & & \\
\hline Poor & 0 & 0 & & \\
\hline
\end{tabular}

$\mathrm{T} 1$ : Residual translation in the coronal plane

A1: Residual angulation in the coronal plane

T2: Residual translation in the sagittal plane

A2: Residual angulation in the sagittal plane

$\mathrm{N}$ : number of repeated radiographs after the first postoperative radiograph

Table 3 Summary of literatures on perfecting orthogonality of radiographs

\begin{tabular}{|c|c|c|}
\hline Method & Title & Author \\
\hline Markers & Intraoperative measurement of mounting parameters for the Taylor Spatial Frame & Gantsoudes et al. [15] \\
\hline Rotation rod & $\begin{array}{l}\text { Improving the accuracy of patient positioning for long-leg radiographs using a Taylor Spatial Frame } \\
\text { mounted rotation rod }\end{array}$ & Ahrend et al. [28] \\
\hline Guide frame & A guide frame for the Taylor Spatial Frame & Kanellopoulos et al. [24] \\
\hline Spirit level & A frame-mounted X-ray guide for the Taylor Spatial Frame & Deakin DE et al. [25] \\
\hline Silhouette technique & $\begin{array}{l}\text { The silhouette technique: improving post-operative radiographs for planning of correction with a } \\
\text { hexapod external fixator }\end{array}$ & Wright et al. [27] \\
\hline Guideline & Improving radiographic imaging for circular frames: the Cambridge experience. & Al-Uzri et al. [29] \\
\hline Additional foot ring & $\begin{array}{l}\text { Improving postoperative radiographs for the parameter measurement of hexapod external fixator } \\
\text { using an additional foot ring }\end{array}$ & Liu et al. [30] \\
\hline
\end{tabular}

healing. Therefore, according to our experience, the three key point trajectory of "distraction-derotation-reduction" is recommended due to the less repeated reduction procedures, shorter duration of reduction, and lower potential radiation exposure, especially in complex fractures with irregular bony ends.

Small sample size in a single-center could be considered as a limitation of this study. Compared with the conventional one-step reduction trajectory, this three key point trajectory requires a bit more work of the surgeon but the superiority of this method was approved.

\section{Conclusion}

Compared with the conventional one-step reduction trajectory, there is not the difference in final clinical outcome, but the staged correction trajectory provides less $\mathrm{X}$-ray repeating and shorter duration of the reduction process. 


\section{Abbreviations}

HEF: Hexapod external fixator; TSF: Taylor spatial frame; AP: Anteroposterior.

\section{Acknowledgements}

Not applicable.

\section{Authors' contributions}

YSL: Conducted the study. Collected, analyzed and interpreted the data. Wrote the manuscript. WF: Interpreted and analyzed the data. Edited the manuscript. $\mathrm{KL}$ : Created and statistical analyzed the data. Edited the manuscript. FYC: Conducted the study and provided the data. XPZ: Conducted the study and prepared Figs. 1-2. HL: Conducted the study and prepared Figs. 3-4. TZ: Provided theoretical guidance. Reviewed the manuscript. AY: Planned the project. Reviewed the manuscript. Yanshi Liu and Fei Wang contributed equally to this study. All authors read and approved the final manuscript.

\section{Funding}

This study was funded by the grants from National Natural Science Foundation of China (No. 82060401).

\section{Availability of data and materials}

The datasets analyzed during the current study are available from the corresponding author on reasonable request.

\section{Declarations}

\section{Ethics approval and consent to participate}

All methods in this study were carried out in accordance with the Declaration of Helsinki. This study was approved by the Ethics Committee of The First Affiliated Hospital of Xinjiang Medical University. Written informed consent was obtained from all patients for their data to be recorded in our study.

\section{Consent for publication}

Not applicable.

\section{Competing interests}

The authors declare that they have no competing interests.

\section{Author details}

'Department of Trauma and Microreconstructive surgery, the First Affiliated Hospital of Xinjiang Medical University, Urumqi, Xinjiang, China. ${ }^{2}$ Department of Orthopaedics, the First Affiliated Hospital of Xinjiang Medical University, Urumqi, Xinjiang, China. ${ }^{3}$ Department of Orthopedics, Shanghai Pudong New Area People's Hospital, Shanghai, China. ${ }^{4}$ Department of Orthopedics, Zigong Fourth People's Hospital, Zigong, Sichuan, China. ${ }^{5}$ Department of Orthopedics and Trauma, Tianjin Hospital, Tianjin, China.

\section{Received: 1 September 2021 Accepted: 1 March 2022}

Published online: 08 March 2022

\section{References}

1. Paley D, Fleming B, Catagni M, Kristiansen T, Pope M. Mechanical evaluation of external fixators used in limb lengthening. Clin Orthop Relat Res. 1990:50-7.

2. Hak DJ, Toker S, Yi C, Toreson J. The influence of fracture fixation biomechanics on fracture healing. Orthopedics. 2010;33:752-5.

3. Mullins MM, Davidson AW, Goodier D, Barry M. The biomechanics of wire fixation in the llizarov system. Injury. 2003;34:155-7.

4. Liu Y, Liu J, Yushan M, Liu Z, Zhang T, Ma H, et al. Management of highenergy tibial shaft fractures using the hexapod circular external fixator. BMC Surg. 2021;21:95

5. Wani N, Baba A, Kangoo K, Mir M. Role of early llizarov ring fixator in the definitive management of type II, IIIA and IIIB open tibial shaft fractures. Int Orthop. 2011;35:915-23.
6. Rogers GP, Tan HB, Foster P, Harwood P. Complex Tibial shaft fractures in children involving the distal Physis managed with the llizarov method. Strategies Trauma Limb Reconstr. 2019;14:20-4.

7. Thabet AM, Gerzina C, Sala F, Jeon S, Lovisetti G, Abdelgawad A, et al. Outcomes and complications with treatment of open Tibial plafond fractures with circular external fixator. Foot Ankle Int. 2021;42:723-33.

8. Keshet D, Eidelman M. Clinical utility of the Taylor spatial frame for limb deformities. Orthop Res Rev. 2017;9:51-61.

9. Potgieter MS, Pretorius HS, Preez GD, Burger M, Ferreira N. Complications associated with hexapod circular fixation for acute fractures of the tibia diaphysis: a retrospective descriptive study at a high volume trauma Centre. Injury. 2020;51:516-21.

10. Sala F, Thabet AM, Capitani P, Bove F, Abdelgawad AA, Lovisetti G. Open supracondylar-intercondylar fractures of the femur treatment with Taylor spatial frame. J Orthop Trauma. 2017;31:546-53.

11. Lim JA, Thahir A, Zhou AK, Girish M, Krkovic M. Definitive management of open pilon fractures with fine wire fixation. Injury. 2020;51:2717-22.

12. Henderson DJ, Barron E, Hadland Y, Sharma HK. Functional outcomes after tibial shaft fractures treated using the Taylor spatial frame. J Orthop Trauma. 2015;29:e54-9.

13. Koo TK, Mak AF. A knowledge-based computer-aided system for closed diaphyseal fracture reduction. Clin Biomech (Bristol, Avon) 2007;22:884-93.

14. Johner R, Wruhs $O$. Classification of tibial shaft fractures and correlation with results after rigid internal fixation. Clin Orthop Relat Res. 1983:7-25.

15. Gantsoudes GD, Fragomen AT, Rozbruch SR. Intraoperative measurement of mounting parameters for the Taylor spatial frame. J Orthop Trauma. 2010;24:258-62.

16. Ilizarov GA. The principles of the Ilizarov method. Bull Hosp Jt Dis Orthop Inst. 1988;48:1-11.

17. Saw A, Phang ZH, Alrasheed MK, Gunalan R, Albaker MZ, Shanmugam R. Gradual correction of proximal tibia deformity for Blount disease in adolescent and young adults. J Orthop Surg (Hong Kong). 2019;27:615534275.

18. lobst CA. Hexapod external fixation of tibia fractures in children. J Pediatr Orthop. 2016;36(Suppl 1):S24-8.

19. Abuomira IE, Sala F, Elbatrawy Y, Lovisetti G, Alati S, Capitani D. Distraction osteogenesis for tibial nonunion with bone loss using combined Ilizarov and Taylor spatial frames versus a conventional circular frame. Strategies Trauma Limb Reconstr. 2016;11:153-9.

20. Ordas-Bayon A, Logan K, Garg P, Peat F, Krkovic M. Ankle arthrodesis using the Taylor spatial frame for the treatment of infection, extruded talus and complex pilon fractures. Injury. 2021;52:1028-37.

21. Rogers MJ, McFadyen I, Livingstone JA, Monsell F, Jackson M, Atkins RM. Computer hexapod assisted orthopaedic surgery (CHAOS) in the correction of long bone fracture and deformity. J Orthop Trauma. 2007;21:337-42.

22. Park DH, Bradish CF. An intraoperative method of calculating the mounting parameters for the Taylor spatial frame using the image intensifier. Ann R Coll Surg Engl. 2011;93:260-1.

23. Kucukkaya M, Karakoyun O, Armagan R, Kuzgun U. Calculating the mounting parameters for Taylor spatial frame correction using computed tomography. J Orthop Trauma. 2011;25:449-52.

24. Kanellopoulos AD, Mavrogenis AF, Kanellopoulos ND, Magnissalis EA, Papagelopoulos PJ. A guide frame for the Taylor spatial frame. J Orthop Trauma. 2009;23:537-40.

25. Deakin DE, Rolands T, Taylor A. A frame-mounted X-ray guide for the Taylor spatial frame. Ann R Coll Surg Engl. 2007;89:729.

26. Liu Y, Yushan M, Liu Z, Liu J, Ma C, Yusufu A. Application of elliptic registration and three-dimensional reconstruction in the postoperative measurement of Taylor spatial frame parameters. Injury. 2020;51:2975-80.

27. Wright J, Sabah SA, Patel S, Spence G. The silhouette technique: improving post-operative radiographs for planning of correction with a hexapod external fixator. Strategies Trauma Limb Reconstr. 2017;12:127-31.

28. Ahrend MD, Finger F, Grunwald L, Keller G, Baumgartner H. Improving the accuracy of patient positioning for long-leg radiographs using a Taylor spatial frame mounted rotation rod. Arch Orthop Trauma Surg. 2021:141:55-61.

29. Al-Uzri M, Thahir A, Abdulkarim A, Krkovic M. Improving radiographic imaging for circular frames: the Cambridge experience. Arch Orthop Trauma Surg. 2020;140:1965-70. 
30. Liu Y, Liu K, Cai F, Zhang T, Yusufu A. Improving postoperative radiographs for the parameter measurement of hexapod external fixator using an additional foot ring. J Orthop Surg Res. 2021;16:668.

31. Gessmann J, Frieler S, Konigshausen M, Schildhauer TA, Hanusrichter $Y$, Seybold D, et al. Accuracy of radiographic measurement techniques for the Taylor spatial frame mounting parameters. BMC Musculoskelet Disord. 2021;22:284

\section{Publisher's Note}

Springer Nature remains neutral with regard to jurisdictional claims in published maps and institutional affiliations.

- fast, convenient online submission

- thorough peer review by experienced researchers in your field

- rapid publication on acceptance

- support for research data, including large and complex data types

- gold Open Access which fosters wider collaboration and increased citations

- maximum visibility for your research: over $100 \mathrm{M}$ website views per year

At BMC, research is always in progress.

Learn more biomedcentral.com/submissions 